\title{
MIDAS
}

Museus e estudos interdisciplinares

4 | 2014

Varia e dossier temático: "Museus, utopia e urbanidade"

\section{Fazer um museu numa ruína moderna}

To build a museum in a modern ruin

\section{Ricardo Carvalho e Joana Vilhena}

\section{(2) OpenEdition \\ Journals}

\section{Edição electrónica}

URL: http://journals.openedition.org/midas/743

DOI: $10.4000 /$ midas.743

ISSN: 2182-9543

\section{Editora:}

Alice Semedo, Paulo Simões Rodrigues, Pedro Casaleiro, Raquel Henriques da Silva, Ana Carvalho

\section{Refêrencia eletrónica}

Ricardo Carvalho e Joana Vilhena, « Fazer um museu numa ruína moderna », MIDAS [Online], 4| 2014, posto online no dia 13 março 2015, consultado no dia 01 maio 2019. URL : http://

journals.openedition.org/midas/743; DOI : 10.4000/midas.743

Este documento foi criado de forma automática no dia 1 Maio 2019

\section{(c) (i) (3) (2)}

Midas is licensed under a Creative Commons Attribution-NonCommercial-ShareAlike 3.0 International License 


\section{Fazer um museu numa ruína moderna}

To build a museum in a modern ruin

Ricardo Carvalho e Joana Vilhena

\section{NOTA DO EDITOR}

Artigo recebido a 25.03.2014

Aprovado para publicação a 02.12.2014

Já não temos começos (Steiner 2002)

\section{Ambiguidade. 0 museu e a galeria}

1 Abordar o programa museu implica hoje reconhecer a experiência deste espaço na vida das comunidades, bem como o posicionamento do seu lugar numa estratégia mais abrangente na política cultural das cidades. Um museu não é, geralmente, uma decisão isolada - partilha de diversas ligações sociais, políticas, até circunstanciais, que transcendem a fixação dos conteúdos. Delinear um museu implica também uma investigação específica - uma investigação disciplinar. Esta investigação incide habitualmente sobre as precedentes posições de diretores de museus, comissários, soluções museográficas e temas de arquitetura. Estas posições provêm de exemplos construídos ou de projetos. Este artigo desenvolve uma abordagem ao museu a partir da arquitetura, e toma como estudo de caso a instalação provisória do MUDE - Museu do Design e da Moda, Coleção Francisco Capelo (daqui em diante apenas MUDE) em Lisboa, um projeto dos autores do texto.

2 Na segunda metade do século XX, o programa museu permitiu um conjunto de reflexões no domínio do espaço e da perceção, sobretudo a partir do universo da arte, que muito 
contribuíram para um alargamento da noção de espaço e suporte museográfico na disciplina da arquitetura. O programa museu conheceu um interesse político na promoção regional das cidades a partir da década de 1980, que motivou o seu destaque na arquitetura contemporânea enquanto tema privilegiado para investigações disciplinares.

No âmbito do pensamento artístico e arquitetónico há convergências e sobreposições no modo de entender o museu. Poder-se-á também referir que a arquitetura foi sendo tomada como foco de interesse da arte contemporânea desde a década de 1960 - e essa abordagem ao espaço e à matéria da construção iria espelhar-se em sentido contrário na disciplina da arquitetura.

4 Não foi apenas dentro da instituição museu que estes conceitos conheceram novas abordagens. O impacto de experiências artísticas e arquitetónicas fora dos meios institucionais foi considerável. Falamos do espaço da galeria e da genealogia da sua transformação até ao predomínio do denominado white cube. No espaço do white cube, a obra de arte apresenta-se isolada de tudo o que eventualmente possa perturbar a sua perceção - num processo a que O' Doherty (1976) apelida de sacralização. Contudo, num processo de pluralidade de posições, ao mesmo tempo que o white cube é progressivamente adotado, massificado e repetido pela instituição museu, alguns curadores, artistas e arquitetos propõem modos concretos de superação desta via - a partir do final da década de 1960. Este texto irá abordar alguns desses exemplos e clarificar a sua contribuição para a conceção contemporânea de espaço expositivo.

5 Não foi apenas o espaço da galeria de arte que permitiu definir conceitos alternativos no domínio do espaço expositivo. Um outro universo menos abordado pelos meios académicos, que é o dos espaços de trabalho dos artistas - o atelier, o estúdio, o armazém, o espaço físico em espera, sem uso definido - motivou um progressivo foco de interesse em espaços previamente não reconhecidos pelas cidades como passíveis de serem reutilizados. Motivou também algumas experiências museográficas que procuraram tirar partido dessa singularidade espacial difícil de captar pelos meios institucionais. A convergência conceptual da galeria e do espaço de trabalho irá permitir extrapolações para o espaço do museu no início do século XXI. Alguns destes exemplos serão abordados neste artigo.

Uma exposição, hoje de relevância histórica no âmbito arte contemporânea, comissariada por Harald Szeemann e intitulada Live in Your Head: When Attitude Becomes Form, determinou formas de ação alternativas. As obras de arte de vários artistas apropriavamse dos pavimentos e das paredes numa informalidade que a instituição museu geralmente não adotara - essas mesmas obras possuíam uma relação de tensão entre si. As características físicas das obras (no domínio daquilo que hoje convencionalmente se designa por Arte Povera e Arte conceptual) reforçavam essa ambiguidade entre precariedade e informalidade, já que muitas recorriam a materiais provenientes de universos tradicionalmente distantes da escultura como o feltro, as luminárias néon, os tubos de aço, os tecidos ou as redes metálicas. 
Fig. 1 - Vista da montagem da exposição

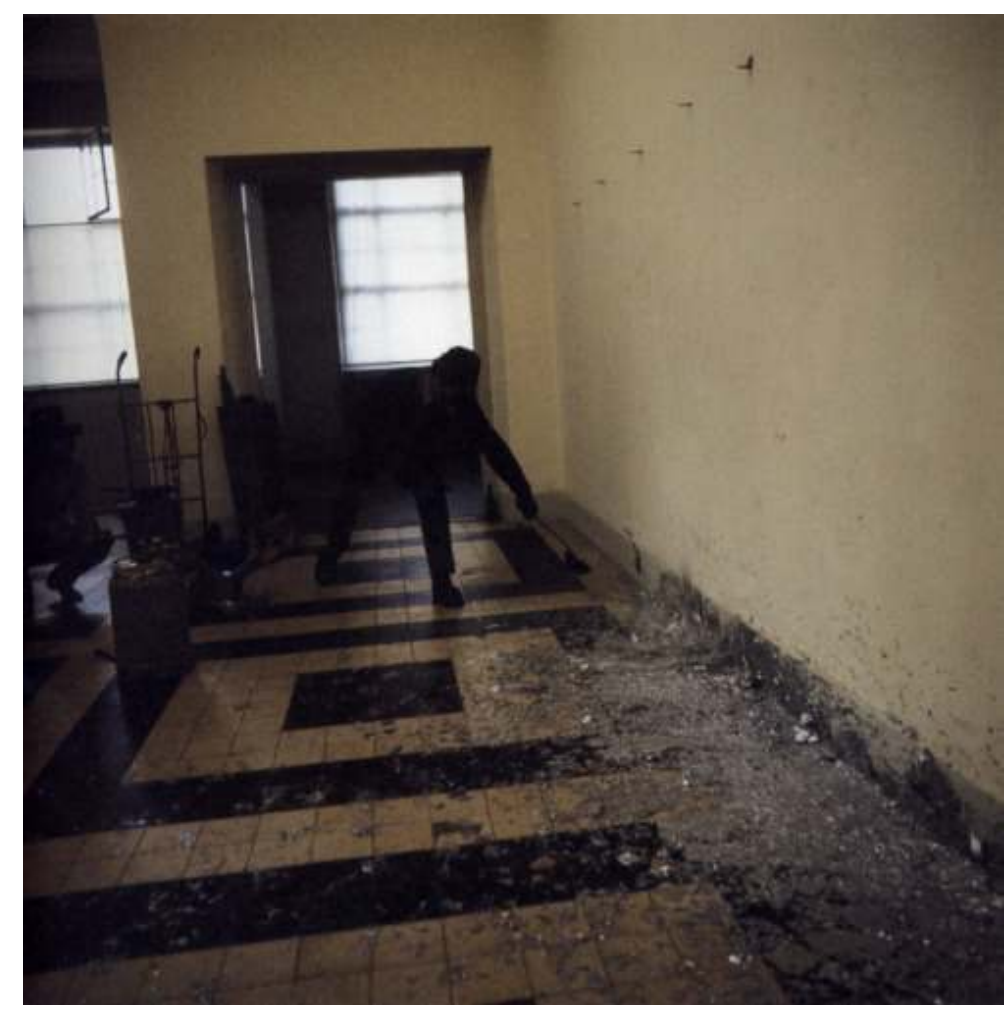

(Richard Serra a montar a peça Splash Piece) Live in Your Head: When Attitude Becomes Form, 1969. Kunsthalle, Berna, Suíça

(c) Fotografia de Harald Szeemann

7 Esta exposição apresentada na Kunsthalle de Berna, na Suíça, uma instituição pública, em 1969, contribuiu para fazer implodir a ideia de construção de um museu neutro, ao mesmo tempo que levantava uma outra questão crucial: o conflito e o diálogo entre os objetos artísticos, a arquitetura propriamente dita enquanto fenómeno físico e social e a curadoria - que neste caso específico era interventiva. Szeemann escreveu no texto de manifesto sobre esta exposição:

The obvious opposition to form; the high degree of personal and emotional engagement; the pronouncement that certain objects are art, although they have not previously been defined as such; the shift of interest away from the result towards the artistic process; the use of mundane objects; the interaction of work and material. (Szeemann 1969, 28)

O curador refere-se à mudança de foco, à translação do objeto para o processo. Ou seja, o lugar que o processo de trabalho ocupava era determinante. Poderia até coincidir com o resultado artístico propriamente dito - numa posição que podemos encontrar em várias obras no domínio da Arte conceptual.

9 Esta etapa de valorização do processo de trabalho (algo que está em curso, inacabado ou sujeito a acerto e verificação) seria crucial para a elaboração do projeto de instalação provisória do MUDE. Por um lado, porque o horizonte temporal da intervenção estava determinado, o que permitia valorizar e extremar soluções não perenes, por outro lado, porque se poderia convocar o processo de construção civil (a obra) como algo assimilado ao processo conceptual do projeto de arquitetura e museografia - em resumo, o trabalho poderia consistir em construir algo que está em curso, revelando o processo. 
Fig. 2 - Vista do atelier do artista Richard Serra

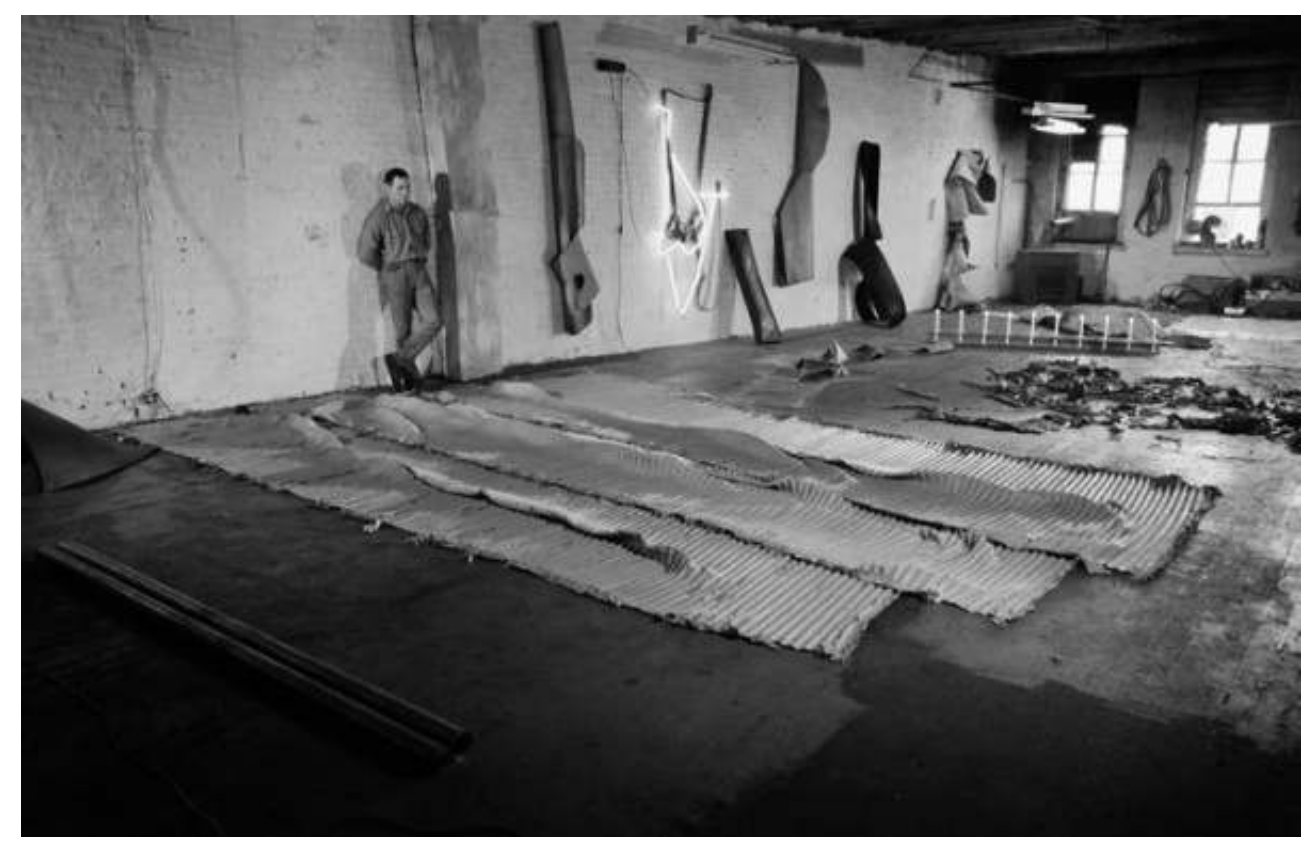

1968, Nova lorque

(c) ARTISTS RIgHTS SOCIETY PHOTO $\odot 2013$ LAWRENCE FRIED

Paralelamente às experiências de curadoria com maior dimensão de radicalidade ocorridas entre o final da década de 1960 e a década de 1970, os espaços de trabalho passaram a contribuir para o enquadramento dos conteúdos artísticos. Artistas como Gordon Matta-Clark nos Estados Unidos ou Anselm Kiefer na Europa utilizaram a arquitetura na sua dimensão física e política para trabalhar determinados temas artísticos e ampliar o objeto da escultura. O primeiro colocou o tema do abandono e dos lugares em espera (casas suburbanas e armazéns industriais) ao centro das suas ações de corte e reinvenção da matéria arquitetónica. Chegou a levar fragmentos para o interior da galeria - soalhos, estruturas de madeira, tabiques. O segundo trabalhou sobretudo com a memória (o monumento e a ruína, os despojos) e com a história da Europa e da Alemanha em particular.

11 Numa imagem do atelier do escultor Richard Serra, em Nova Iorque, feita em 1968, emerge uma outra dimensão do espaço expositivo. Parece existir uma ambiguidade entre a matéria da arquitetura (o pavimento, as paredes, as vigas, as janelas) e o material do trabalho de escultura deste artista - que está espalhado pelo pavimento, pelas paredes e recorre às matérias da construção civil, como o chumbo, o metal, as chapas, entre outros, para se formalizar. Todos os materiais parecem ser provenientes do edifício - dos elementos construtivos daquele espaço. Essa ambiguidade, entre arte e construção, pelo menos no ponto de partida, explorada em profundidade por este escultor, contribuiu para a fixação da proposta de arquitetura para o MUDE, em Lisboa. 
Fig. 3 - Vista do atelier do artista Mark Rothko

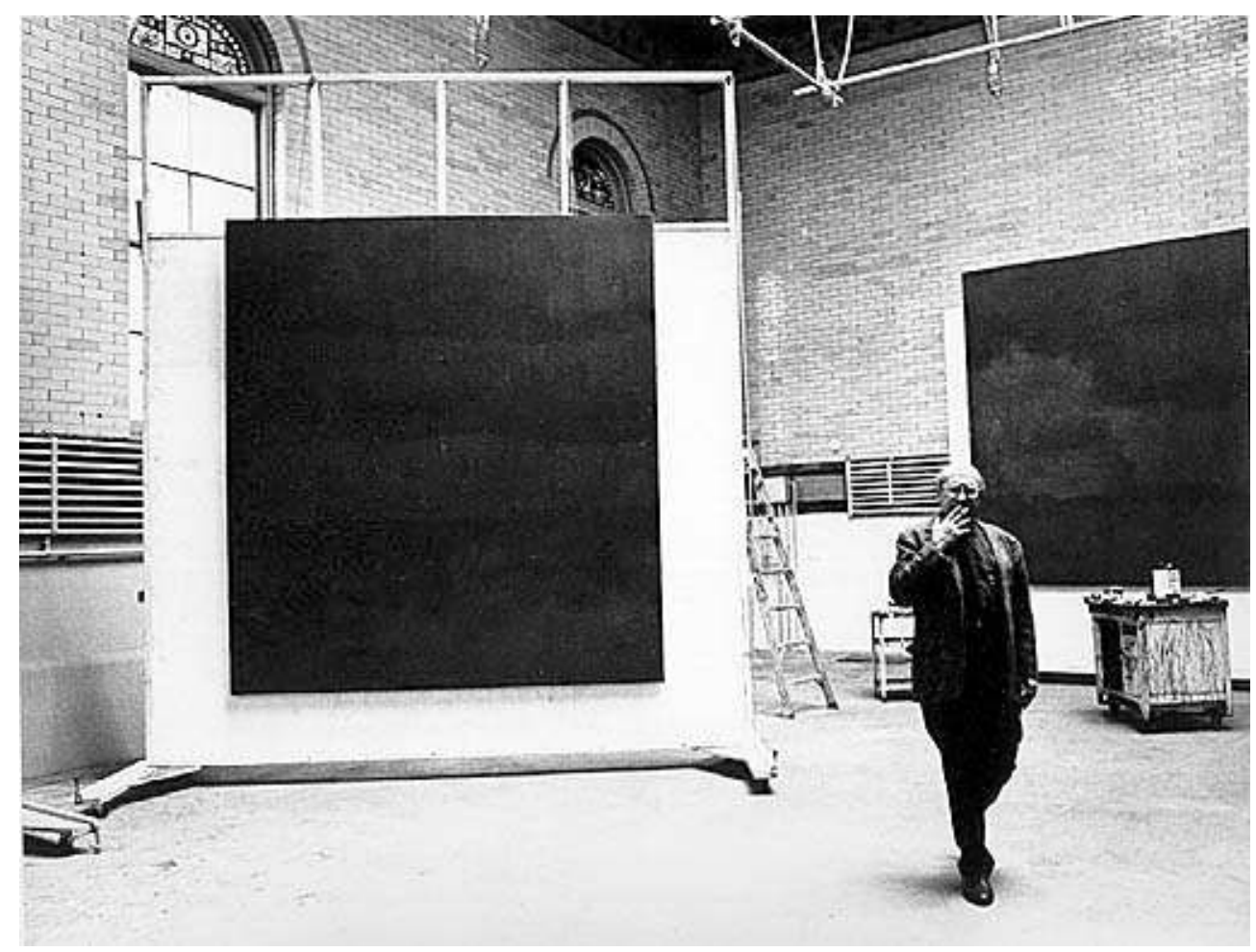

1964, NOVA IORQUE

(c) Fotografia de Hans Namuth. Center for Creative Photography, University of Arizona (c) 1991 Hans Namuth Estate

Outra referência que revela a capacidade dos espaços de trabalho de poderem contribuir para uma crítica ao espaço museográfico é a do atelier do pintor Mark Rothko, em Nova Iorque. Pelas fotografias de Hans Namuth podemos perceber o modo livre de disposição das telas no espaço - a sua mutabilidade permitida pelo suporte e a procura de libertação da parede. Os artistas não expõem habitualmente o seu trabalho com o efeito de sacralização a que assistimos nos museus - o espaço de trabalho abdica do plinto e da parede branca com a iluminação difusa. O caso mais celebrado e estudado desta possibilidade foi o espaço da primeira versão da Factory, em Nova Iorque, gerido pelo artista Andy Warhol, entre 1962 e 1968. A principal característica espacial da Factory era ter sido um armazém e estar forrada a folha de alumínio. A Factory iniciou um longo lastro de desejo por um universo mais informal e geralmente pouco calculado - aquilo que poderíamos descrever como espaço da imprevisibilidade. 
Fig. 4 - Vista do Atelier do artista Olafur Eliasson, 2013, Berlim

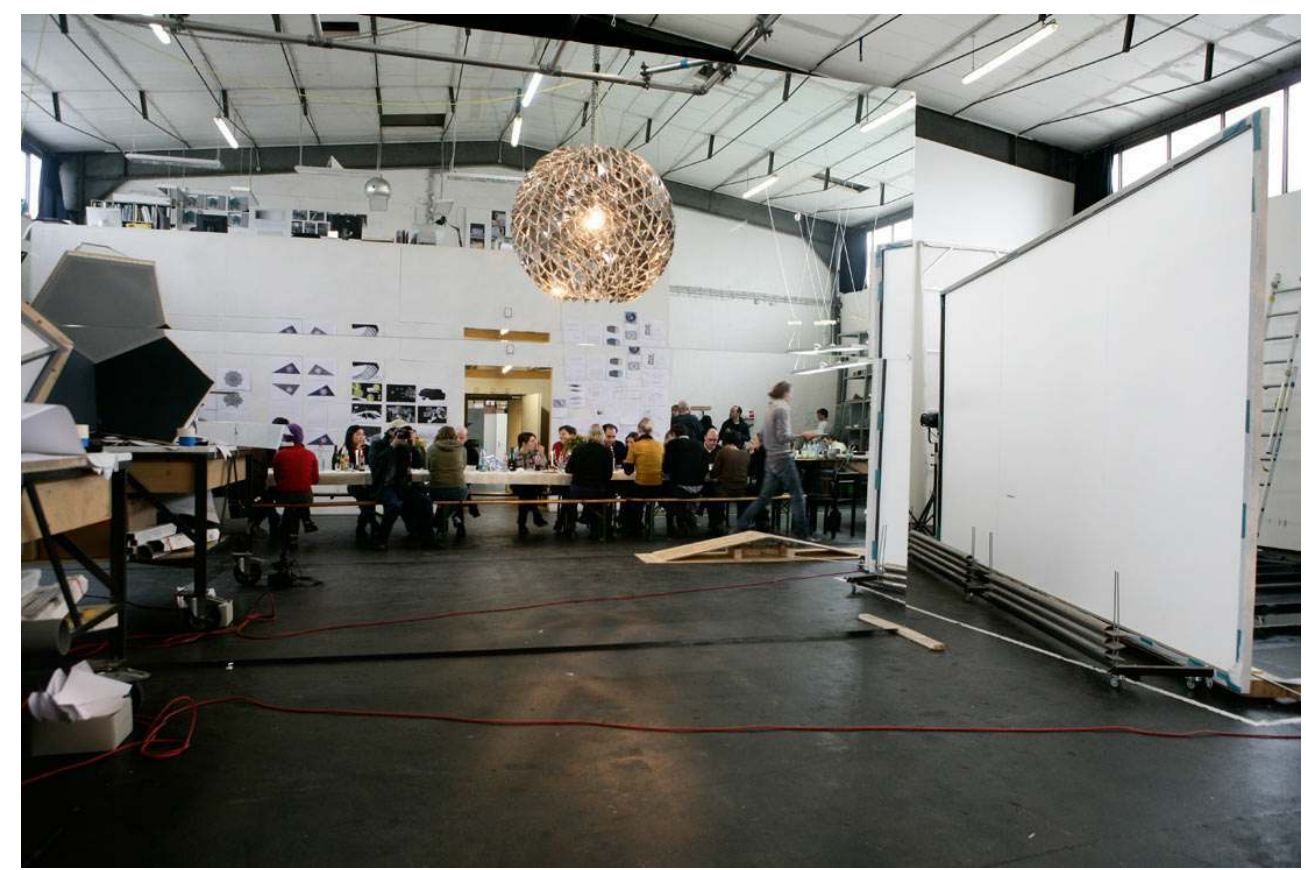

(C) Olafur Eliasson Studio

Também hoje podemos encontrar experiências e reflexões em torno do espaço de trabalho. $O$ atelier do artista Olafur Eliasson, em Berlim, uma antiga fábrica em tijolo, foi adaptado para poder acolher performances, conferências, encontros e refeições coletivas. É um atelier que transcende o espaço de trabalho e se pode tornar um primeiro rastilho de hipótese de museu laboratório experimental - lugar de reflexão, produção, promoção e de exposição. Na fotografia que selecionámos, vê-se um espelho que reflete a coexistência de vários momentos - o trabalho dos assistentes do artista; reuniões com empresas; exposições. O lugar da produção - o lugar do processo - está acessível. Afirma Eliasson: «Art is not for the museums that are then for the audience; art is for the audience, and museums should support the artistic content by making it accessible to the audience» (Eliasson 2012, 195).

Parece legítimo propor a partir deste ponto uma argumentação a partir de uma ideia de informalidade em arquitetura. A informalidade, que coincide com a proposta da Attitude that Becomes Form de Szeemann é um tema de difícil fixação no mundo da construção física de elementos que definem espaço. Mas poder-se-ia afirmar que essa informalidade permite experienciar um museu como um lugar onde as pessoas estão próximas dos conteúdos e onde estes se dispõem com um caráter de proximidade. Da investigação sobre a informalidade para construir a argumentação inicial e, entre as várias referências encontradas, o trabalho de uma curadora norte-americana tornou-se fundamental na compreensão do potencial dos edifícios na sua relação com a arte e a arquitetura. Chamase Alanna Heiss e foi a responsável pela criação entre 1975 e 1976, em Queens (Nova Iorque), de um centro de arte contemporânea, numa antiga escola primária, a Public School $n .1$ - que se transformou em PS1. 
Fig. 5 - Átrio do PS1, 1975-1976, Nova lorque
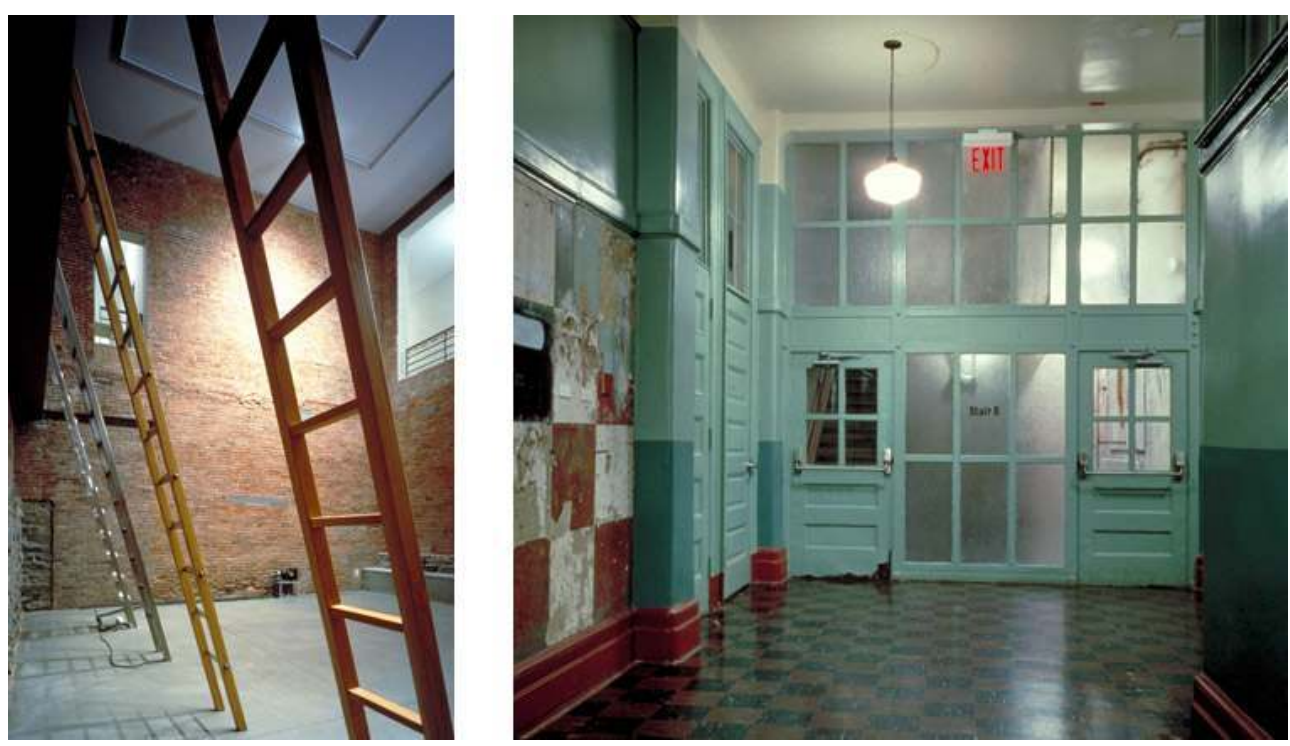

(C) MoMA/PS1

O PS1 foi uma das obras resultantes do Institute for Art and Urban Resources que Heiss também fundou. Trata-se de uma associação sem fins lucrativos que inclui artistas, curadores, arquitetos, a municipalidade e mecenas que procuravam edifícios na zona de Nova Iorque para reutilizar como espaços de exposição. Estes resíduos do mundo contemporâneo, assim reinventados e metamorfoseados, fizeram parte de uma série de trabalhos que hoje estão assimilados nas estratégias contemporâneas, mas que nos anos 1970 foram determinantes para a crítica ao white cube e também para a crítica a uma arquitetura corporativa que iniciava a sua incursão na produção de museus no mundo ocidental - um movimento que continua em curso no presente.

O trabalho feito no PS1 centra-se na reutilização de uma antiga escola primária. A radicalidade do projeto consiste precisamente na alteração mínima ao edifício original. 0 edifício não perdeu o caráter arquitetónico original. A sua matriz está presente e a arte que aí é exposta está em confronto, conflito ou diálogo com o espaço. Enquanto tema de arquitetura poder-se-ia afirmar que o projeto não consistiu numa transformação do edifício-escola. Foi uma outra coisa: uma monitorização da coexistência de identidades (entendida em duplo sentido - sociais e físicas) que, ainda hoje, se podem perceber como tal. Outra característica deste projeto curatorial prendia-se com o convite feito aos artistas para trabalhar com as comunidades locais: afro-americanas e ítalo-americanas. A primeira exposição do PS1 chamou-se Rooms.

Com as propostas do escultor Donald Judd para Marfa, no Texas, Estados Unidos, um processo iniciado em 1971, encontramos uma operação que faz a síntese entre a prática artística, a posição curatorial, a museografia e a arquitetura. Nesta pequena cidade anteriormente utilizada como interposto militar, Judd realizou vários projetos para a Fundação Chinati e para si próprio, hoje conhecidos como "La Mansana de Chinati". Judd intuiu a possibilidade de aí realizar uma síntese bauhausiana para um tipo de arte específica. Ao longo de três décadas vários edifícios foram sendo transformados de modo a poderem acolher espaços de exposição, de encontro e de trabalho. Desde o início do 
processo que o artista o define como um programa conceptual alternativo à instituição museu.

The installation of my work and that of others is contemporary with its creation. The work is not disembodied spatially, socially, temporally as most museums. The space surrounding my work is crucial to it: as much thought has gone into the installation as into a piece itself. The installations in New York and Marfa are a standard for the installation of my work elsewhere. (Judd 1977, 8-9)

Donald Judd radicalizou esta posição, trabalhando com peças site-specific de vários artistas (Dan Flavin, Ingólfur Arnarsson, John Chamberlain, Richard Long e Roni Horn, para nomear os que estão representados em permanência na Fundação Chinati) e tirando partido do caráter serial e industrial da arquitetura que acolhia os trabalhos. A primeira decisão foi uma adaptação leve dos edifícios ao novo uso. Os materiais da arquitetura não são revestidos (a madeira, a betonilha, o aço, o tijolo) e alguns processos de construção vernaculares, como o tijolo de adobe, são recuperados para projetos de muros ou de paredes interiores, convocando a comunidade para trabalhar em algumas obras.

Fig. 6 - Vista do atelier de arquitetura do artista Donald Judd

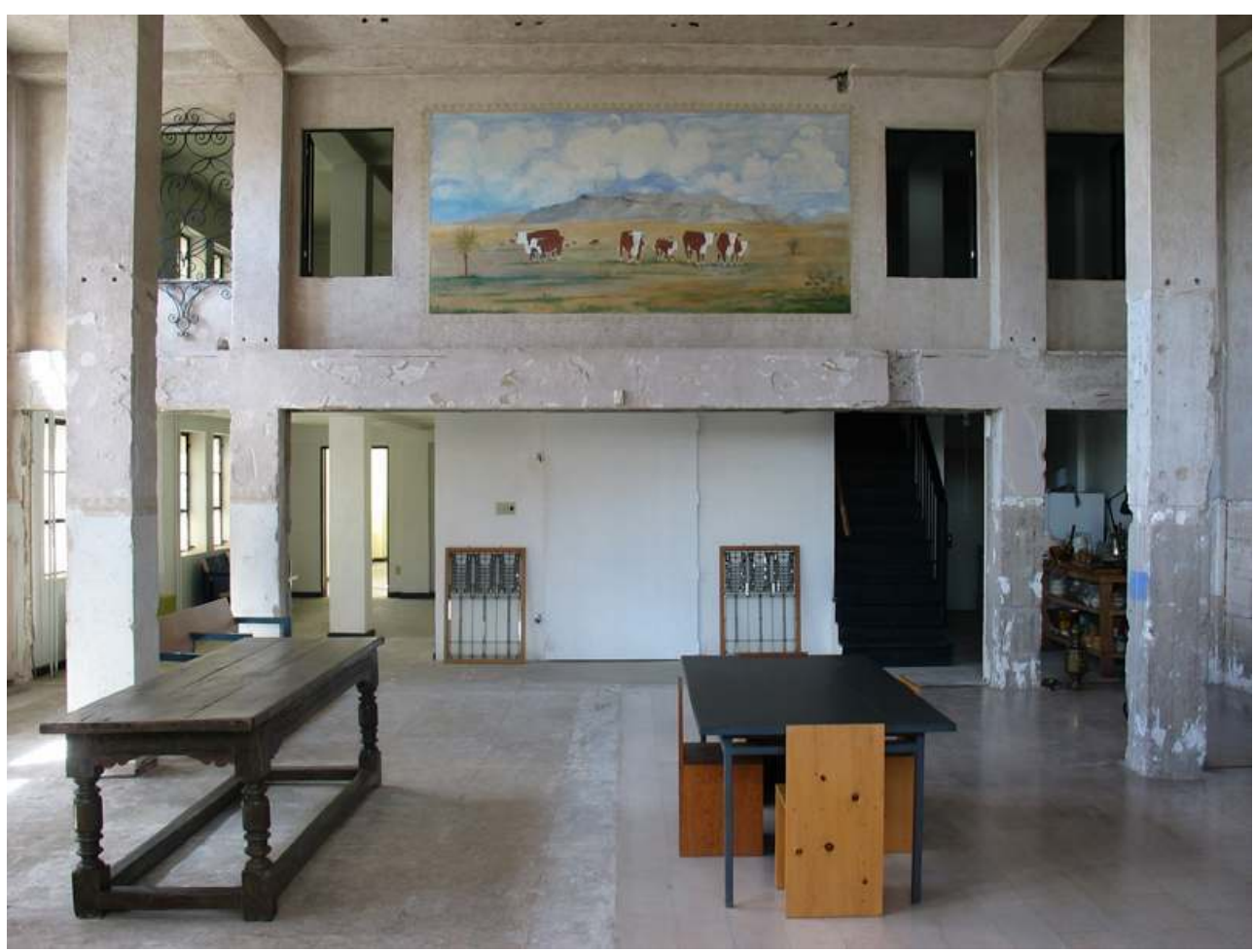

1971-1994, MARFA (ESTADOS UNIDOS)

(c) Judd Foundation

Os espaços de exposição da Arena, Edifício Oeste e do Pavilhão Sul de Artilharia não recorrem à utilização de luz elétrica; o percurso do sol concretiza o ciclo de vivência daqueles espaços - numa variação constante em oposição à luz difusa e constante do museu de matriz moderna. Em síntese, Judd procura uma sobreposição de materiais aos edifícios existentes, permitindo a sua leitura como continuum histórico, e recorre à luz natural como matéria primordial do espaço.

No atelier de arquitetura de Donald Judd, um espaço despojado de revestimentos, convivem elementos e artefactos que habitualmente não coexistiriam: mobiliário antigo, 
pintura naïve, duas janelas de uma casa desenhada por Frank Lloyd Wright, que foi demolida, e o mobiliário desenhado pelo próprio. Trata-se de uma arquitetura que é um suporte e um revelador das marcas do tempo, que o artista assume como ideal para receber estas e outras apropriações.

21 No projeto para o Pavilhão Sul de Artilharia Judd constrói uma estrutura de betão-armado. A expressão exterior (de abóbada) não coincide com a interior - uma laje plana em betão aparente. Esta intervenção, feita com pilares e vigas, para se relacionarem especificamente com as 48 esculturas de aço que aí estão implementadas de forma permanente, constitui uma das propostas mais polissémicas de Marfa. Com o percurso do sol, vão-se alterando as sombras, os brilhos e a perceção das obras de arte no espaço. Não é possível dissociar a intervenção artística do sentido arquitetónico da intervenção.

Fig. 7 - Vista da sala de exposições do Palais de Tokyo

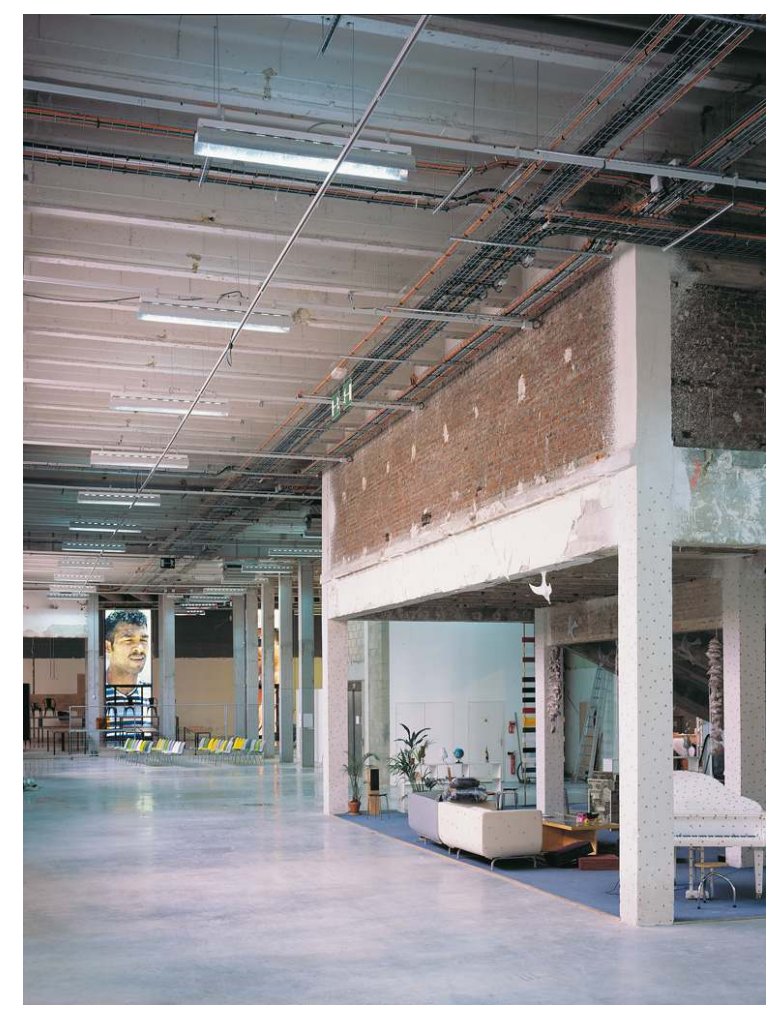

2001, PARIS

(c) Ricardo Carvalho

O Palais de Tokyo, originalmente construído para a Exposição Internacional de 1937 em Paris, e, desde o final de 2001, reconvertido em Centro de Criação Contemporânea é um projeto da dupla de arquitetos Lacaton \& Vassal. No interior convivem informalmente uma livraria, um bar e um restaurante, dispersos em torno de uma série de quatro espaços de exposição. Estas atividades parecem provisória e circunstancialmente instaladas e a estrutura original do edifício, em betão, está descarnada e à vista.

23 A livraria está envolta numa rede de arame, como as redes que separam os campos desportivos no espaço público. As paredes de betão denunciam marcas de elementos que já não existem. Pelo teto correm todas as infraestruturas. Um piso abaixo está o bar, que é uma amálgama de materiais. A cozinha industrial está em relação direta com o bar, onde aliás é necessário ir buscar o que se pretende. As salas de exposição são marcadas pelas 
claraboias de duas águas, que Anne Lacaton e Jean Philippe Vassal introduziram para levar a luz natural ao interior. Neste Centro de Criação Contemporânea todas as partes são colocadas no todo, lidas como acontecimentos isolados.

o Palais de Tokyo pode ser lido como um encontro fortuito entre as teorias sobre a impossibilidade da instituição museu proposta pela Internacional Situacionista e uma proposta de reutilização dos edifícios urbanos em espera. Este projeto constitui-se como uma condição transitória (a deriva situacionista) que elege o espaço público como espaço de criação artística. Formaliza-se pela recusa (não é claro se é conceptual ou ideológica ou ambas) de utilizar materiais nobres, como pedra, madeiras ou vidros sofisticados, deixando a ossatura original do edifício, e por isso revelando-o como espaço novo, desconhecido por estar despido de revestimentos e ornamentos que originalmente o caracterizaram. A intervenção não revela contudo o que é novo e o que é encontrado. Esta obra deve ser vista sobretudo como uma ação.

\section{Fazer um museu}

O projeto do MUDE consiste numa intervenção no edifício do antigo Banco Nacional Ultramarino (BNU), na baixa pombalina de Lisboa. 0 edifício que chegou até nós (iniciado em 1952) é da responsabilidade do arquiteto Cristino da Silva. O projeto original do BNU é da autoria do arquiteto Tertuliano Marques, que previu a ocupação integral do quarteirão da baixa pombalina. Com a demolição dos edifícios pombalinos, e a alteração do cadastro inicial, este projeto criou uma singularidade urbana e abriu caminho a sucessivas intervenções ao longo do século XX. O espaço de atendimento do banco caracterizava-se pelo piso térreo inteiramente dedicado aos clientes, com uma forte relação urbana com as quatro ruas que envolvem o quarteirão. A sua porta monumental, em aço, na rua Augusta parecia demonstrar o desejo de afirmação da instituição. As portas laterais permitiam o acesso direto da rua ao interior - a uma sala-quarteirão.

$\mathrm{O}$ antigo edifício do BNU possuía um ambiente marcado pelos materiais de grande solidez e sofisticação construtiva. O seu desenho possuía uma matriz eclética e variava de piso para piso. Já na década de 1950 estava muito distante da arquitetura mais radical do Movimento Moderno, ou, até, de edifícios que procuravam fazer a ponte ou a síntese entre o universal e o local. A arquitetura deste banco remetia o visitante para um outro tempo, mais relacionado com os ambientes das instituições de França e Europa Central. Pode afirmar-se que o banco se aproximava da cultura vienense, de obras de arquitetos como Otto Wagner. Os escassos documentos fotográficos que chegaram até nós mostramnos um piso térreo com um balcão em pedra capaz de desenhar por si só todo o espaço $\mathrm{e}$ marcar o quarteirão pelo interior. Em 2009 foi transformado no MUDE, um museu que se apoderou dos resíduos de um banco colonial. 
Fig. 8 - Vista da sala de exposição permanente do MUDE

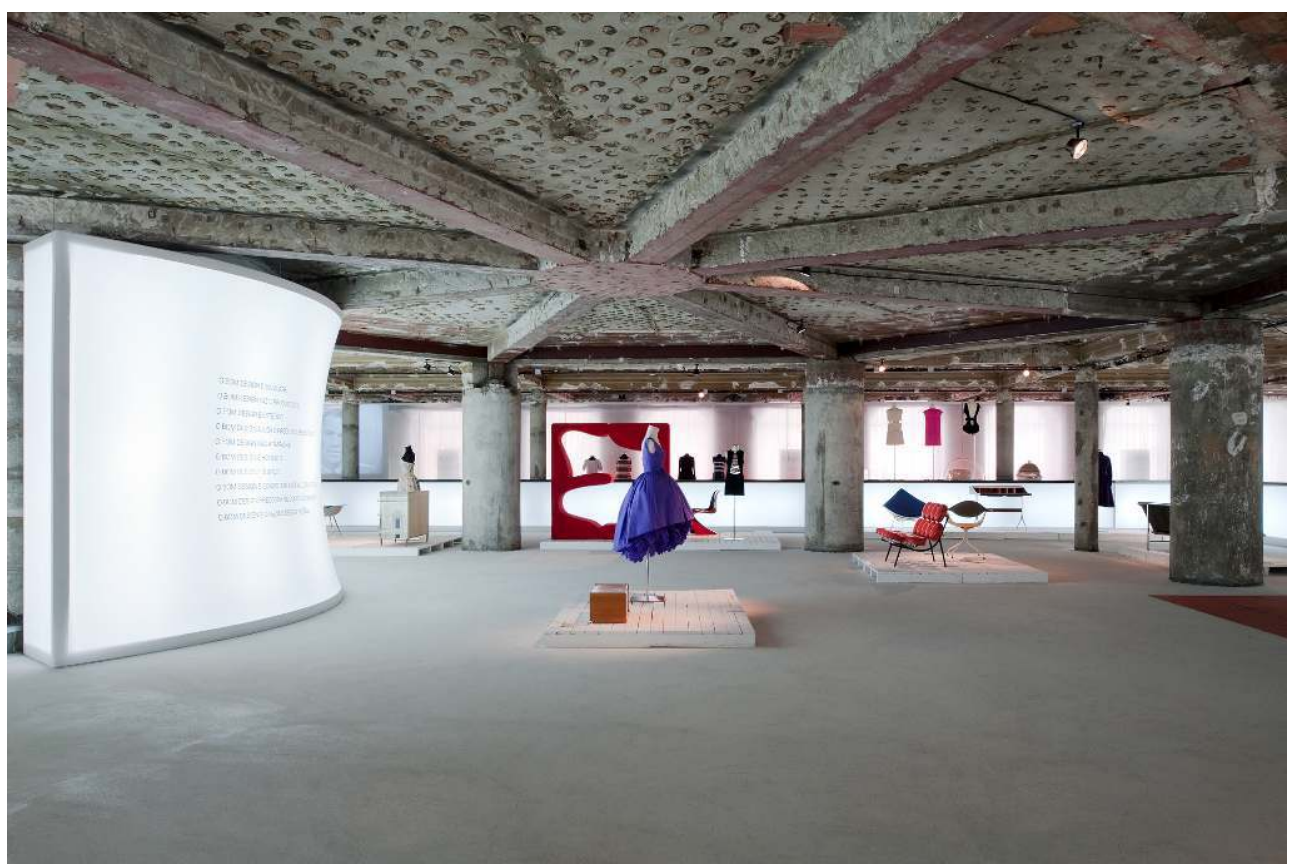

2009, LISBOA

(c) Fernando Guerra/FG+SG

No início da década de 2000 o banco mudou de proprietário e foi profundamente adulterado, tendo sido o projeto de transformação interrompido abruptamente pela tutela da preservação patrimonial. Esta interrupção não impediu que o edifício ficasse destruído, sem os revestimentos originais e com a estrutura de betão à vista. 0 edifício ficou em espera numa baixa pombalina de Lisboa também em espera. $O$ projeto de instalação provisória do MUDE faz-se com a surpresa de um encontro com uma ruína do século XX, uma ruína moderna.

o projeto para o museu baseia-se numa primeira leitura que fizemos do edifício em ruína, bem como numa estratégia de projeto de baixo custo. Uma afirmação da reciclagem, da reutilização e da possibilidade de construir um museu com premissas diferentes das habitualmente instituídas.

Trata-se do único quarteirão na baixa pombalina de Lisboa passível de ser visto no interior sem obstruções significativas, um quarteirão como um espaço interior - uma sala em ruína com predomínio sobre quatro ruas que definem a malha urbana. 0 projeto partiu desta singular possibilidade percetiva e propôs a instalação do novo programa sem recurso à construção de paredes. Foram necessárias demolições pontuais nos dois primeiros pisos para clarificar a matriz da intervenção. A supressão tornou-se uma estratégia alternativa à construção.

O projeto faz-se com luz. A iluminação artificial apodera-se de alguns elementos construídos e investe na imaterialidade da luz para reforçar a presença da estrutura em betão armado e, principalmente, das peças da coleção. A luz artificial apodera-se dos elementos construídos, das caixas de elevadores e do antigo balcão de atendimento dos clientes do banco. A luz natural nunca deixa de entrar no museu. É o equilíbrio e a 
variação entre uma e outra fonte de iluminação que permitem que o ambiente do museu seja sempre distinto ao longo do dia.

31 Para além da presença expressionista da estrutura em betão à vista, o projeto faz-se também pelos materiais provenientes do universo da construção civil - reforçando a noção de processo, de algo que está em curso. Estes materiais e a sua conjugação não se encontram na museografia ou na arquitetura dos museus. Estão presentes no processo genérico de construção da arquitetura e de algumas obras de arte e, por isso, foram convocados.

32 As telas, utilizadas no cobrimento de estaleiros, serviram para envolver a relação com a rua. As telas brancas velam o exterior, mas permitem ver as pessoas que passam, como silhuetas, que permanentemente percorrem os enquadramentos visuais entre as peças da coleção.

33 As paletes pintadas de branco, material em madeira de empilhamento, que se utilizaram na museografia, pretendem valorizar, por oposição, as peças que acolhem. As paletes permitiram também abdicar do desenho do plinto, aproximando as peças da coleção do pavimento. Esta é a sua condição natural já que muitas são peças de mobiliário.

O pavimento foi parcialmente coberto - onde foi necessário reconstruir as lajes em betão armado - com uma pintura industrial branca de tinta refletante, utilizada nas estradas e que à noite cintilam com os faróis dos automóveis. Também no MUDE o pavimento branco cintila com as paletes brancas que recebem as peças.

Fig. 9 - Vista da sala de exposição permanente do MUDE

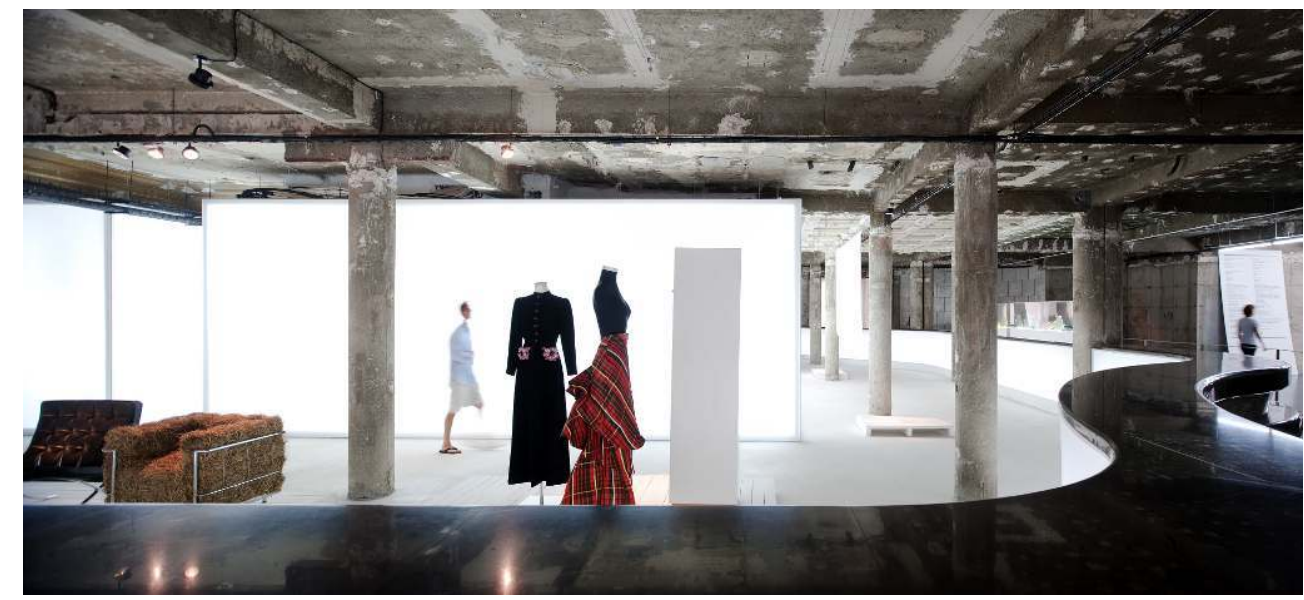

2009, LISBOA

(C) Fernando Guerra/FG+SG

As peças da coleção ocupam o espaço de modo informal e estabelecem uma relação de proximidade com o visitante. Estas estão colocadas próximas do pavimento em paletes ou em cima do antigo balcão de atendimento. A noção de plinto foi abolida. Os espaços complementares, como a livraria, o auditório circular ou cafetaria deixam-se contaminar pelos espaços expositivos. Em limite, o museu poderá ocupar estes espaços com peças da coleção. A cafetaria, com a sua mesa única em cortiça negra, acusa a presença do museu com uma janela que o avista, mas também a das ruas da cidade.

O museu foi pensado como uma alternativa ao white cube e como um desafio à noção de neutralidade. A noção de espaço de trabalho e de informalidade também contribuiu para 
fixar a proposta de um museu que se sabia estar em curso. A genealogia da intervenção provém das estratégias de reutilização desenvolvidas por projetos de arquitetura, arte e curadoria como foi demonstrado ao longo deste texto. Os exemplos mais relevantes para este processo foram o PS1, em Nova Iorque, e a Fundação Chinati, em Marfa, por questionarem as noções instituídas para o museu moderno e terem procurado propor alternativas específicas para um determinado programa curatorial. A reutilização museográfica de espaços construídos com usos distintos na sua génese constitui o seu principal legado.

Outra contribuição prende-se com o posicionamento das peças ou obras de arte no espaço. Nos exemplos referidos o confronto entre a arquitetura e a arte pressupõe a não neutralidade e a ambição simbiótica entre um e outro campo. Também este legado foi utilizado no MUDE, no sentido em que a leitura dos conteúdos não pode abdicar do seu suporte e em vários momentos as peças são colocadas no espaço sem a medição de plintos.

A intervenção no Palais Tokyo, em Paris, constituiu uma referência pela sua capacidade de negar a neutralidade do museu, estabelecendo uma atitude provocatória face à formalidade das instituições e assumindo o espaço como uma praça pública. 0 projeto de instalação provisória do MUDE está mais próximo, conceptualmente, da ação temporária, da instalação, bem como de uma proposta de radical flexibilidade na apropriação do espaço. Com a adesão intensa das pessoas ao museu, a estratégia mostrou poder passar de provisória a fundacional.

\section{BIBLIOGRAFIA}

AA.VV. 2010. "Museums in Queens: Queens Museum Of Art, P.S. 1 Contemporary Art Center, New York Hall of Science, Greater Astoria Historical Society.” [sl.]: BOOKS LLC.

Cohn, David, Ricardo Carvalho, e J. V Arquitetos. 2009. "Museum of Design and Fashion, Lisbon." ARCHITECTURAL RECORD 9: 66-71.

Eliasson, Olafur, e Philip Ursprung, eds. 2012, Studio Olafur Eliasson: An Encyclopedia. Koln: Taschen.

Heiss, Alanna. 2012. "Placing the Artist." Consultado em março 4, 2014. http://www.moma.org/ learn/resources/archives/EAD/MoMAPS1_If.

Jauss, Hans Robert. 2002. Pequeña Apología de la Experiencia Estética. Barcelona: Ediciones Paidós.

Judd, Donald, ed. 1993. Spaces. Ostfildern: Cantz Verlag.

Judd, Donald. (1977) ed. 2005. The Complete Writings. Nova Scotia: The Press of the Nova Scotia College of Art and Design.

Kramer, Sibylle. 2014. Exhibition Design. Zurique: Braun.

Lepik, Andres, ed. 2014. Show and Tell Collecting Architecture. Berlin: Hatje Cantz.

McGuirk, Justin. 2009. “MUDE: Destruction Was Preservation.” Icon 77: 38-40.

Monteys, Xavier. 2011. Rehabitar en Nueve Episodios. Barcelona: Ed. Lampreave. 
O’Doherty, Brian. 1976. “Inside the White Cube: Notes on the Gallery Space.” Artforum.

Riso, Vincenzo. 2011. Modern Building Reuse: Documentation, Maintenance, Recovery and Renewal. Guimarães: Universidade do Minho. http://hdl.handle.net/1822/28957.

Rocha, Paulo Mendes da. 2007. “A Cidade Para Todos.” Jornal Arquitetos 227 (abril/junho).

Rorimer, Anne. 2001. New Art in the 60s and 70s: Redefining Reality. New York: Thames \& Hudson.

Steiner, George. 2002. Gramáticas da Criação. Lisboa: Relógio D’Água.

Szeemann, Harald. (1969) ed. 2007. Individual Methodology. Zurich: JRP RINGER Kunstverlag.

Uffelen, van Chris. 2011. Contemporary Museums: Architecture, History, Collections. [Salenstein]: Braun.

Wallis, Brian. 2002. “Public Funding.” In Alternative Art, New York, 1965-1968. Minneapolis: University of Minnesota Press.

\section{RESUMOS}

Definir um projeto de arquitetura e museografia implica uma investigação específica - uma investigação disciplinar. Esta incide habitualmente sobre as posições precedentes no domínio da curadoria, da arte e da arquitetura. Este artigo desenvolve uma abordagem ao espaço do museu a partir da arquitetura, e toma como estudo de caso a instalação provisória do MUDE - Museu do Design e da Moda, Coleção Francisco Capelo em Lisboa (Portugal). Convocam-se exemplos construídos em que foi possível realizar a síntese entre a arte e a arquitetura, como é caso do PS1 de Nova Iorque, da Fundação Chinati em Marfa, nos Estados Unidos, e o Centro de Criação Contemporânea Palais Tokyo, em Paris. Abordam-se ainda os espaços de trabalho dos artistas e a capacidade experimental que estes possuem, bem como a problemática da conceção do espaço de museu na cultura contemporânea.

An architectural project in the realm of museography implies a specific research - a disciplinary one. This research merges eventually on precedent positions in the field of curating, art and architecture. This paper proposes an architectural approach to the space of museum, taking as case study the Museum of Design and Fashion of Lisbon (Portugal). It takes also an interpretation of several built works where is possible to underline a synthesis between art and architecture. Such is the case of PS1 in New York, the Chinati Foundation in Marfa, USA and the Centre for Contemporary Creation Palais Tokyo in Paris. The text approaches the interpretation of artist working spaces to underline its experimental condition and discusses the conception of the museum space in the contemporary culture.

ÍNDICE

Keywords: museum, ruin, reuse of space, museum architecture, Museu do Design e da Moda Coleção Francisco Capelo, contemporary art centre

Palavras-chave: museu, ruína, reutilização espacial, arquitetura de museu, Museu do Design e da Moda - Coleção Francisco Capelo, centro arte contemporânea 


\section{AUTORES}

\section{RICARDO CARVALHO}

Licenciou-se em Arquitetura pela Faculdade de Arquitetura da Universidade Técnica de Lisboa em 1995. É doutor em Arquitetura (2012) pelo Instituto Superior Técnico da Universidade Técnica de Lisboa. Em 1999 fundou o escritório Ricardo Carvalho + Joana Vilhena Arquitetos. É professor associado no Departamento de Arquitetura da Universidade Autónoma de Lisboa. Foi professor do mestrado internacional Architektur Studium Generale da Universidade do Brandemburgo BTU Cottbus, na Alemanha (2009-2013), e professor visitante na Universidade de Navarra, em Espanha (2013-2014). Entre 2005 e 2008 foi codiretor do Jornal Arquitetos. É crítico de arquitetura do jornal Público desde 1999. rcjvarquitectos@gmail.com

\section{JOANA VILHENA}

Licenciou-se em Arquitetura pela Faculdade de Arquitetura da Universidade Técnica de Lisboa em 1998. Em 1999, fundou o escritório Ricardo Carvalho + Joana Vilhena Arquitetos. Foi professora convidada do seminário de arquitetura Arquiteturas da Raia - Elvas em 2001. No mesmo ano concebeu a cenografia do espetáculo My Name is Wilde, Oscar Wilde do coreógrafo Francisco Camacho. Foi editora de projeto Jornal Arquitetos, entre 2005 e 2008. Atualmente, prepara a sua tese de doutoramento na Universidade de Évora. 